\title{
Trends in vascular pharmacology research in the Department of Pharmacology and Clinical Pharmacology, Faculty of Medicine, Comenius University, Bratislava
}

\author{
Viera KRISTOVÁ, Milan KRIŠKA, Róbert VOJTKO, Miriam PETROVÁ, Silvia LíŠKOVÁ, \\ Radoslav VILLÁRIS, Zoltán VARGA, Martin WAWRUCH \\ Department of Pharmacology and Clinical Pharmacology, Faculty of Medicine, Comenius University, Bratislava, Slovak Republic
}

ITX040111R04 • Received:20 February 2011 • Revised:09 March 2011 • Accepted: 12 March 2011

\begin{abstract}
Research in the Department of Pharmacology started to focus intensively on fetal circulation in the 60s. Results of experiments contributed to clarification of the conversion of fetal circulation type to the adult type: the mechanism of the ductus arteriosus closure, examination of fetal and neonatal pulmonary vessel responses. In the early 80s, increased attention was dedicated to fetal vascular endothelium, later on to vascular reactivity in relation to the endothelium in adult animals. We developed original models of vascular endothelial damage using the perfusion method (repeated vasoconstrictive stimuli, deendothelization by air bubbles). We developed a new technique for in vitro endothelial loss quantification on Millipore filters. Under in vitro conditions, the protective effects of sulodexide and pentoxifylline on vascular endothelium were evaluated. In recent years were studied protective effects of selected substances in vivo in models of endothelial damage (e.g. stress, toxic tissue damage, diabetes mellitus, hypertension). The role of potassium channels in the hypertension model was studied in cooperation with the Czech Academy of Sciences. Assessment of vascular reactivity in the diabetic model was significantly improved by computer. In addition to experimental work, the department is solving problems of clinical pharmacology - especially drug risk evaluation (non-steroidal anti-inflammatory drugs). Recently, we have dealt with pharmacoepidemiological studies in geriatric patients and with cardiovascular risk of NSAIDs in relation to pharmacotherapy. The results of these studies may be an impulse for targeted problem solving in our experiments.
\end{abstract}

KEY WORDS: vascular responses; models of endothelial damage; computer-based studies; cardiovascular drugs; NSAIDs; adverse drug effects

\section{Introduction}

Research in cardiovascular pharmacology has a long tradition in our department and in the past decade it has undergone significant changes. In the 60 s, we focused on fetal blood vessels, and particularly on the role of fetal shunts, such as the ductus arteriosus, in the conversion from a fetal to an adult type of circulation. Research achievements of Kovalčík (1963) contributed significantly to the clarification of the mechanism of ductus arteriosus closure and especially of the crucial role of oxygen in

Correspondence address:

Prof. Viera Kristová, MD., PhD.

Department of Pharmacology and Clinical Pharmacology,

Faculty of Medicine, Comenius University

Sasinkova 4, 81108 Bratislava, Slovak Republic

TEL.:+421-2-59357 232 •E-MAIL: viera.kristova@fmed.uniba.sk this closure. The role of prostaglandins, kinins and other vasoactive substances, as well as the myogenic activity of ductus arteriosus, was studied in other research work of the department (Kriška \& Kovalčík, 1973; Smieško et al., 1978). With time, the topic of fetal vessels logically continued in the study of pulmonary and umbilical vessels reactivity (Kristová et al., 1986), which in the perinatal period contributes crucially to the transformation of fetal circulation to the adult type. In addition to the study of effects of vasoactive substances (biogenic amines, kinins, prostaglandins) and medicaments (ambroxol, glucocorticoids) on pulmonary vessels, research was extended to evaluate effects of endothelin on the pulmonary circulation of fetal sheep (Cassin et al., 1991). Parallel with the research of vessel reactivity in ontogenesis, our department also examined the effects of hormones on vascular responses. In the early 80 s, increased attention 
was given to fetal vascular endothelium, starting from the morphological aspect and later on to the vessel response (Babál et al., 1987). Subsequently, we focused our study on vascular reactivity in relation to the endothelium in adult animals (Kriška et al., 1989). We evaluated the impact of factors increasing the risk of endothelium damage - as the duration of vessel storage and application of vasoconstrictive substances (Kristová et al., 1993). Results of these experiments led to their targeted use in further experiments. We designed in vitro models of vascular endothelial damage using the perfusion method - method of repeated vasoconstrictive stimuli induced by norepinephrine, vascular deendothelization by air bubbles, and endothelial damage by perfusion with activated polymorphonuclear leukocytes. Under conditions of the perfusion method, we developed an original technique to quantify the endothelial loss on Millipore filters after the use of deendothelization stimuli (Babál et al., 1992). After verification of experimental models of endothelial damage in vitro, we started to evaluate effects of different drugs and substances on the endothelium. First we investigated effects of nonsteroidal anti-inflammatory drugs, which by inhibiting the synthesis of vasodilator prostaglandins potentiated the vasoconstrictive responses of femoral and renal arteries (Kristová et al., 2000; 2002).

Under conditions in vitro, the potential protective effect of sulodexide and pentoxifylline on vascular endothelium was evaluated (Kristová et al., 1995; 2000; Babál et al., 1996). In the last years, we studied endotheliumprotective effects of selected substances in experimental models of endothelial damage in vivo; particularly in the stress model, the model of toxic tissue damage by carbon tetrachloride and in the diabetic model (Kristová et al., 2006; 2008; Babál et al., 2006). Mechanism of vascular reactivity in relation to potassium channels in hypertensive animals were revealed in experiments carried out in cooperation with the Institute of Physiology, Academy of Sciences, Czech Republic (Líšková et al., 2007). The results obtained by traditional methods of vascular response evaluation often fail to show an authentic view on contractile responses (phasic and tonic component). Digital recording of contractile responses using modern software enables mathematical analysis of perfused vessel reactivity. We obtained original results, which quantify a wide set of parameters not investigated so far (Dedík et al., 2003; Vojtko et al., 2010).

In cooperation with clinical institutes, our department has been dealing for a long time with some problems of

Table 1. Effect of sulodexide (SLX) on number of circulating endo thelial cells in plasma $[E C / 10 \mu l]$ in control (C), SLX treated (SLX), diabetic (DM) and diabetic rats treated with SLX (DM+SLX) in 10-week diabetes mellitus.

\begin{tabular}{cccc} 
C & SLX & DM & DM+SLX \\
$\mathbf{1 . 8 8}$ & $\mathbf{2 . 3 8}$ & $\mathbf{3 . 8 8}$ & $\mathbf{2 . 2 5}$ \\
$(0.75 ; 2.25)$ & $(1.75 ; 3.00)$ & $(3.25 ; 5.75)^{* * * *+}$ & $(1.75 ; 3.50)^{\#}$ \\
\hline
\end{tabular}

Data are expressed as medians and their $95 \%$ confidence intervals, ${ }^{* * * *} p<0.0001$ : Control vs. DM, ${ }^{++} p<0.01$ : SLX vs. DM, ${ }^{\#} p<0.02$ : DM vs. DM+SLX. clinical pharmacology - mostly based on experimental results. As the most serious problem we consider drug risk evaluation, concerning particularly analgesics. Adverse effects of nonsteroidal anti-inflammatory drugs in highrisk patients were evaluated in cooperation with National Institute of Rheumatic Diseases. In collaboration with clinical departments, problems of pharmacotherapy of peripheral circulation disorders were studied (Kriška et al., 2002; Rajec et al., 2007).

Recently, the staff of our department has focused on the pharmacoepidemiological studies in geriatric patients (Wawruch et al., 2008) and on the cardiovascular risk of NSAIDs in relation to pharmacotherapy (Varga et al., 2010). The results of these studies may be an impulse for targeted problem solving, especially in clarifying serious cardiovascular disorders resulting from drug interactions.

\section{Selected results from the recent period}

\section{A. Experimental part}

\section{Evaluation of endothelium-protective effects of sulodexide on experimental model of diabetes mellitus}

Diabetes mellitus (DM) is generally associated with many cardiovascular complications accompanied with development of endothelial dysfunction or damage. Therefore, the usage of some drugs, as statins, ACE inhibitors, pentoxifylline, may have a protective effect on the endothelium. Based on our previous experience with sulodexide (glycosaminoglycan composed of heparin-like and dermatan fractions), we decided to evaluate its endothelium-protective effects in the model of streptozotocininduced DM. We focused mainly on measurement of the number of circulating endothelial cells in peripheral blood as a morphological marker of endothelial injury and on evaluation of acetylcholine-induced relaxations of the rat mesenteric artery as a marker of endothelial function.

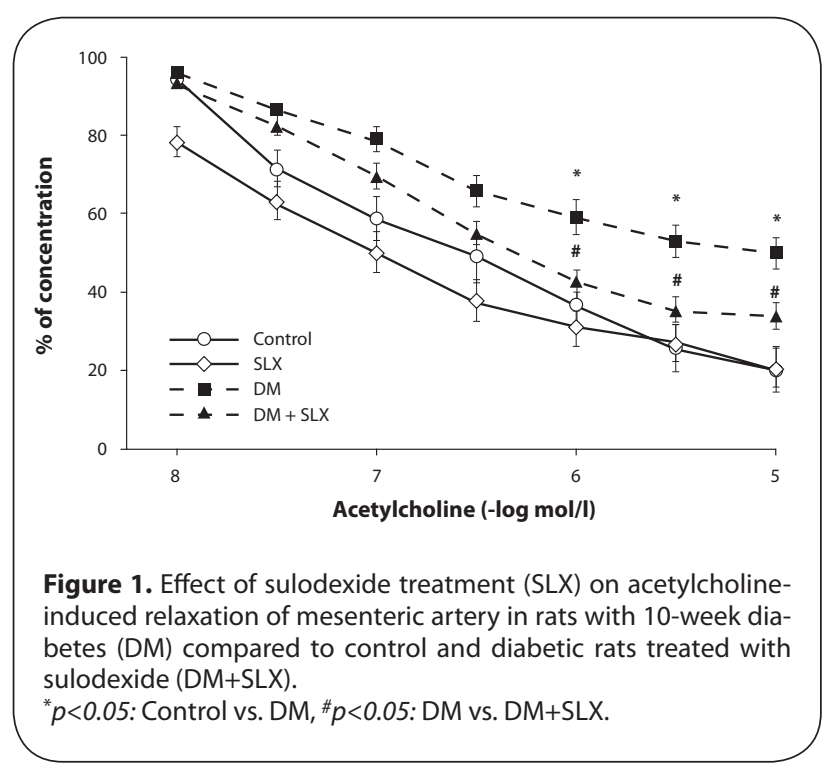




\section{Methods}

The following groups of animals were used in experiments: control (C, saline solution), sulodexide (SLX, $100 \mathrm{UI} / \mathrm{kg} /$ day), DM, induced by administration of streptozotocin (STZ in the dose $30 \mathrm{mg} / \mathrm{kg} /$ day i.p. over 3 consecutive days), $\mathrm{DM}+\mathrm{SLX}$. Treatment with sulodexide lasted 10 weeks. Isolated vessels were cut into rings for measurement of isometric contractions. The number of endothelial cells in blood was measured in Bürker's chamber according to a previously described method (Kristová et al., 2006).

Results

Ten weeks of diabetes significantly impaired acetylcholine-induced relaxations of isolated mesenteric arteries compared to controls (Figure 1). SLX treatment improved endothelium-dependent relaxation in mesenteric arteries although the control level was not reached. Increased endothelemia was found in diabetic animals compared to the controls, which is in agreement with results of our previous study (Zúrová-Nedelčevová et al., 2006). SLX significantly decreased the number of circulating endothelial cells (Table 1). The obtained results demonstrate that sulodexide has endothelium protective effects in streptozotocin-induced diabetes. The favorable effects of SLX in peripheral occlusive arterial disease were confirmed in clinical studies (Gaddi et al., 1996).

\section{Effects of L-NNA and indomethacin on vascular tone of femoral arteries in Wistar-Kyoto and spontaneously hypertensive rats}

Prevention and treatment of hypertension have been intensively studied, but the mechanisms of hypertension remain still elusive. Hypertension is the leading risk factor of cardiovascular diseases. Cardiac output and peripheral resistance regulate blood pressure. Our group focuses on the regulation of vascular tone, which determines peripheral resistance. There are several relaxing and constricting factors, mostly produced by the endothelium, which control vessel diameter, blood flow and vascular tone. The main vasodilating factors produced by the endothelium are nitric oxide (NO), endothelium derived hyperpolarizing factor (EDHF) and prostaglandins $\left(\mathrm{PGI}_{2}, \mathrm{PGE}_{2}\right.$, $\mathrm{PGD}_{2}$ ). The basic vasoconstrictors include endothelins, thromboxane $\mathrm{A}_{2}\left(\mathrm{TXA}_{2}\right)$ and prostaglandins $\left(\mathrm{PGG}_{2}\right.$, $\mathrm{PGH}_{2}$ ). Endothelium-derived constricting factor (EDCF) is probably a product of cyclooxygenase activity, but this factor has not been identified until today.

\section{Methods}

Our experiments are oriented on the effect of endotheliumderived relaxing (NO) and constricting (EDCF) factors in norepinephrine (NE)-induced contraction. Isolated femoral arteries of 6-month-old normotensive Wistar-Kyoto rats (WKY) and 6-month-old spontaneously hypertensive rats (SHR) were placed in on isometric Mulvany-Halpern myograph. Contraction of femoral arteries with intact endothelium were induced by cumulative doses of NE $\left(10^{-9}-10^{-5} \mathrm{~mol} / \mathrm{l}\right)$. The presence of endothelium was tested by acetylcholine application. NE-induced contraction response curves were constructed under control conditions as well as in the presence of the NO synthase inhibitor $\mathrm{N}(\omega)$-nitro-L-Arginine (L-NNA; $10^{-4} \mathrm{~mol} / \mathrm{l}$ ) and the cyclooxygenase inhibitor indomethacin (IME; $\left.10^{-5} \mathrm{~mol} / \mathrm{l}\right)$

\section{Results}

Our results showed that the NE-induced contraction was augmented in vessels isolated from hypertensive animals. The application of L-NNA increased NE-induced contraction in WKY (Figure 2), but was almost without effect in vessels from SHR. Inhibition of cyclooxygenase markedly impaired NE-induced contractions of femoral arteries of WKY (Figure 2) and SHR.

This impairment was more pronounced in arteries of SHR. We suggest that one possible mechanism of enhanced contractility of vessels during hypertension may be explained by the action of endothelium-derived constricting factor.

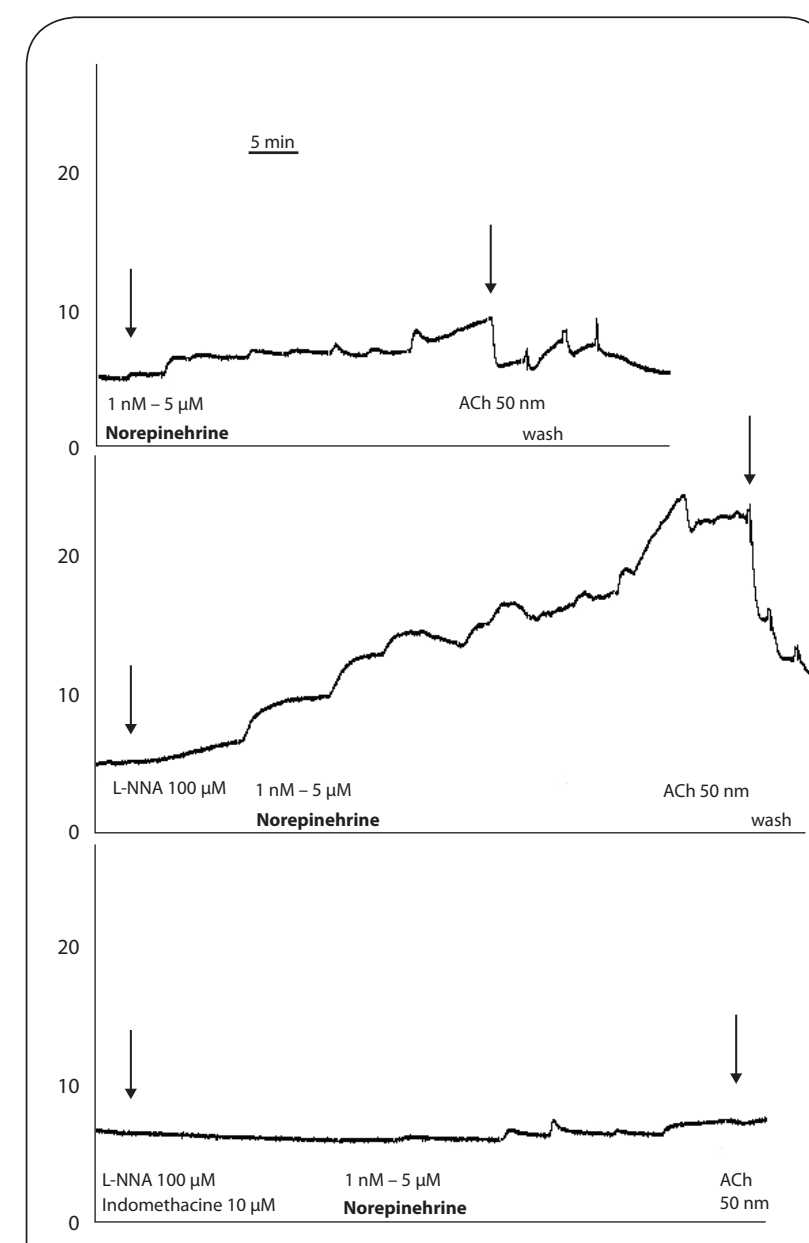

Figure 2. Reactivity of isolated femoral artery with intact endothelium (original records from myograph), Wistar-Kyoto rats. Horizontal axis: time in min. Vertical axis: wall tension in $\mathrm{mN} / \mathrm{mm}$. Ach - acetylcholine, arrows indicate application of initial norepinephrine or acetylcholine dose.

At the top: norepinephrine-induced contraction.

In the middle: norepinephrine-induced contraction in the presence of L-NNA (N( $\omega)$-nitro-L-Arginine).

At the bottom: norepinephrine-induced contraction in the presence of L-NNA and IME (indomethacin). 


\section{Contribution of computer-based modeling to}

\section{assessment of vascular reactivity of diabetic rats}

Evaluation of contractile responses of perfused vascular segments in vitro is traditionally based mainly on determination of the maximum response - amplitude $\left(p_{\max }\right)$ and in some cases on the time needed from the start of the record to reach this peak $\left(t_{\text {max }}\right)$. Such descriptive methods of evaluation are related to data extraction from graphic records of contractions obtained by analog recorders and loaded with subjective inaccuracy of evaluator and a lower reproducibility of the acquired data.

Substantial enrichment of the results of our experimental work was provided by the involvement of new software, using the measurement card recording the contraction response of isolated segments digitally. This enabled quantification and evaluation of a wide set of contractile response parameters, whose determination was not possible by routine descriptive methods. Digital recording of the vessel segment responses to series of succesively increasing doses of norepinephrine was followed by computational modeling determining the resulting parameter values of the segment reactivity. In comparison with analog data extraction, no information gets lost two key parameters measurable by descriptive procedures $\left(p_{\text {max }}, t_{\text {max }}\right)$ quantify computer methods more rapidly and more precisely.

\section{Methods}

Computer-based modeling of digital records of contractions is based on general system theory and uses the analysis of the properties of the system tested through modeling output responses (contractions) to defined inputs (single doses of norepinephrine). The initial step of this analysis is a data-number reduction by standard algorithm, which from originally recorded approximately 250 points retains 30-40 representative points for the course of every

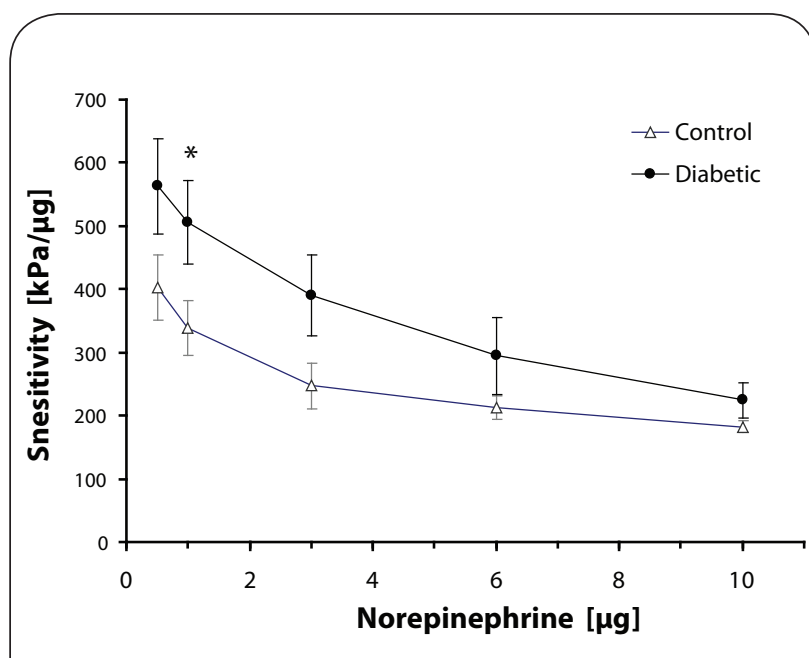

Figure 3. Sensitivity of renal artery segments. Comparison between control group and diabetic. Values are given as mean \pm SEM, ${ }^{*} p<0.05$. contractile response. For the next analysis each artery segment is considered as dynamic system $H$ and computerbased modeling determines a representative set of model parameters, as defined by the system transfer function $H(s)$ :

$$
H(s)=G \frac{a_{0}+a_{1} s+a_{2} s^{2}+\ldots+a_{n} s^{n}}{1+b_{1} s+b_{2} s^{2}+\ldots+b_{m} s^{m}}
$$

where $G, a_{0}, \ldots . a_{n}, b_{1}, \ldots . b_{m}$ are the parameters of the model, $n$ and $m$ are the highest values of numerator, respectively denominator of the polynomial $H(s)$. The values of the transfer function as an argument of complex variable $s$, represent the ratio of the output and input of system $H$ after the Laplace transformation. The modeling procedures used were described by Dedík et al. (2003). The final result of modeling is to obtain the representative model curves of contractile responses and quantification of defined model parameters. These include the most important and characteristic ones for the contractile response - vascular sensitivity $S$ (determined by the parameter $G$, in our model $S=G$ ), mean time of vasoconstrictor response $M T V R$ and the rate constant of relaxation $k_{r e l}$.

Sensitivity of the renal artery segment determines the ratio of the area under curve of the measured profile of contractile response and norepinephrine dose. Mean time of vasoconstrictor response represents the time point of centroid of this profile. Rate constant of relaxation stands for the lowest from the absolute values among the members in the denominator of the polynomial $H(s)$ equation. The sensitivity $S$ in relation to the effect of norepinephrine represents its intensity, $M T V R$ its duration and $k_{r e l}$ its regression (Dedik et al., 2003).

\section{Results}

Our results in the model of streptozotocin-induced diabetes in rats were obtained by application of the computerbased modeling procedures for detailed data extraction. On the one hand, values of descriptive parameters $p_{\text {max }}$ and $t_{\text {max }}$ did not show statistically significant differences in the reactivity of renal artery segments between the control and diabetic group. On the other hand, the course of the curves showing values of the key parameter $S$ for each dose of norepinephrine (range $0.5-10 \mu \mathrm{g}$ ) showed distinct differences with statistical significance at the dose of $1 \mu \mathrm{g}$ (Figure 3).

Evaluation of parameters MTVR (Figure 4A) and $k_{\text {rel }}$ (Figure 4B) for selected doses with the highest sensitivity at 0.5 and $1 \mu \mathrm{g}$ and the model type $1-4(n=1, m=4)$ showed difference between the control and diabetic group, but without statistical significance. The model parameter $S$ and $k_{r e l}$ values suggest a slower pressure decrease in the vascular segment after reaching the peak value in the diabetic group compared to control. Based on these results, we expect disturbance of the wall elasticity of the renal artery segments tested which may increase vascular rigidity (Vojtko et al., 2010). Such alterations associated with diabetic angiopathy have been documented by several 

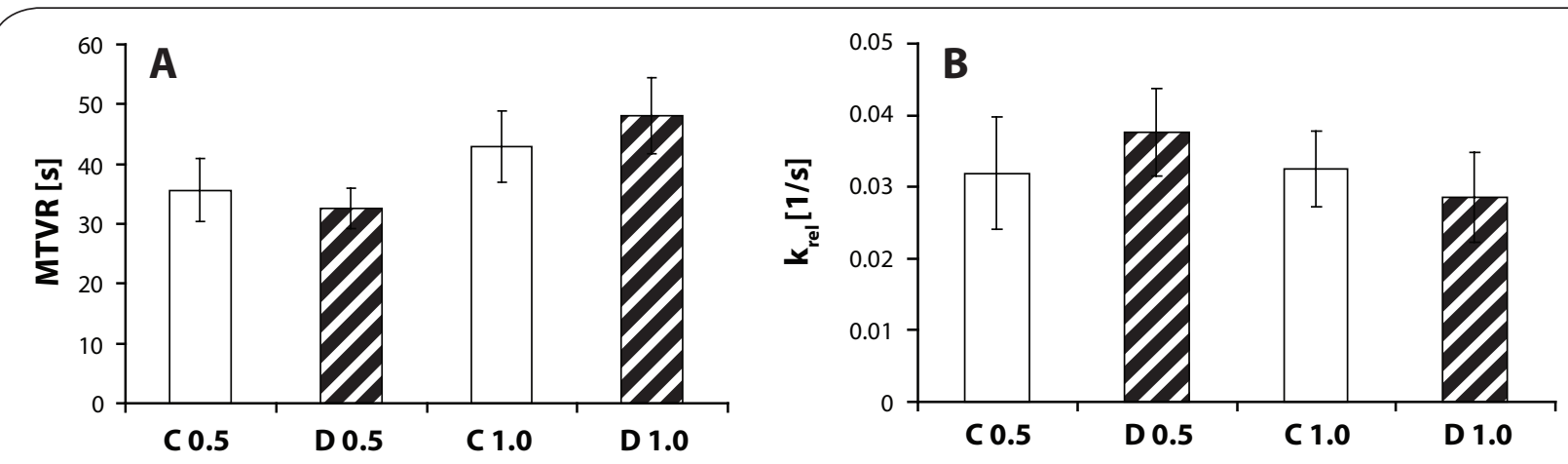

Figure 4. Mean time of vasoconstrictor response $(\mathbf{A})$ and the rate constant of relaxation (B) of renal artery segments at norepinephrine doses 0.5 and $1.0 \mu \mathrm{g}$. C 0.5 - control group, dose $0.5 \mu \mathrm{g} ; \mathrm{C} 1.0$ - control group, dose $1.0 \mu \mathrm{g} ; \mathrm{D} 0.5$ - diabetic group, dose $0.5 \mu \mathrm{g}$; D 1.0 - diabetic group, dose $1.0 \mu \mathrm{g}$. Values are given as mean $\pm \mathrm{SEM}$.

clinical and experimental studies (Lagaud et al., 2001; Sivitz et al., 2007). Computational modeling as a methodological approach shows a new previously unavailable way to precise evaluation of elasticity and other essential functional properties of the vessel wall using the perfusion method, which belongs to in vitro methods closest to physiological conditions.

The described mathematical modeling of digitally recorded contractile responses meets the expectations of accuracy and high reproducibility of data extraction, representing an improvement of the traditional assessment of analog records. It may offer a new view by providing a more detailed and exact description of responses to different substances on vessel segments, which seems to be a significant progress compared with routine descriptive methods.

\section{B. Clinical part}

Cardiovascular drugs potentially inappropriate for elderly patients Persons aged $\geq 65$ years are more susceptible to adverse drug reactions compared to younger people. Changes in drug pharmacokinetics and pharmacodynamics, frequent non-compliance, polymorbidity and polypharmacy contribute to a greater frequency of drug-related problems (Turnheim, 2003). Higher occurrence of adverse effects in elderly patients is associated particularly with the administration of certain drug. Therefore several lists of

Table 2. Potentially inappropriate cardiovascular drugs used in treatment of elderly patients.

\begin{tabular}{|cc|}
\hline Drug & Frequency $(\%$ of $\mathbf{n = 3 4 5 )}$ \\
\hline digoxin* & $44(12.8)$ \\
\hline ticlopidine & $28(8.1)$ \\
\hline amiodarone & $19(5.5)$ \\
methyldopa & $5(1.4)$ \\
doxazosin & $3(0.9)$ \\
\hline
\end{tabular}

digoxin in doses $>0.125 \mathrm{mg} /$ day (except when treating atrial arrhythmias) potentially inappropriate medications for elderly patients were published at the end of the $20^{\text {th }}$ and the beginning of the $21^{\text {st }}$ century (McLeod et al., 1997; Fick et al., 2003). These lists include drugs with increased risk of adverse effects if they are administered to patients aged 65 or more. Other reasons for including a medicine into such lists are high probability of drug-drug interaction and lack of information on the efficacy of the drug in elderly patients in accordance with the requirements of evidencebased medicine. The Beers criteria published in 2003 represent an internationally recognized list of potentially inappropriate medications and they reflect current knowledge in the field of gerontopharmacology.

Methods

The sample of our study ( $\mathrm{n}=345)$ was selected from 524 patients aged $\geq 65$ years hospitalized in a municipal hospital during the time period of August 1, 2004 to March 31, 2005. Patients who died during hospitalization and those with incomplete documentation were excluded from the study. All medications at the time of hospital admission were recorded for each patient. Cardiovascular medications potentially inappropriate for older patients were identified using modified Beers criteria published in 2003 (Fick et al., 2003).

Results

The mean age of the whole group $(n=345)$ was $76.9 \pm 7.4$ years. The study population consisted of 206 (59.7\%) women and 139 (40.3\%) men. At the time of hospital admission, 65 (18.8\%) out of 345 patients were treated with at least one potentially inappropriate medication (Table 2). The most frequently prescribed potentially inappropriate medicine was digoxin at a dose $>0.125 \mathrm{mg} /$ day (except when treating atrial arrhythmias), followed by ticlopidine and amiodarone. The high use of digoxin at doses $>0.125 \mathrm{mg} /$ day may be explained by the frequent occurrence of chronic heart failure in the evaluated group as well as by remaining prescription habits. Ticlopidine was the most frequently prescribed potentially inappropriate medication also in the study of Onder et al. (2005). The authors explain this finding by unavailability of the 


\begin{tabular}{lcc}
\hline Table 3. Diagnoses indicating increased risk of CVS adverse effects \\
\hline Diagnoses & $\begin{array}{c}\text { Number of } \\
\text { patients }\end{array}$ & $\begin{array}{c}\% \text { of the } \\
\text { study group }\end{array}$ \\
\hline Arterial hypertension & 64 & $57.1 \%$ \\
Chronic heart failure & 47 & $42.0 \%$ \\
Ischemic heart disease & 46 & $41.1 \%$ \\
Diabetes mellitus & 33 & $29.5 \%$ \\
\hline
\end{tabular}

safer alternative clopidogrel in Italy at the time of their analysis (1997-1998). Similarly the prescription limitation caused by the high price of clopidogrel contributed to the high prevalence of ticlopidine at the time when our study was carried out. The situation is changing due to current availability of cheaper generic variants of clopidogrel.

Rational attempts to reduce the use of potentially inappropriate medications can have a positive impact on the healthcare system. Our results underline the importance of paying more attention to the topic of pharmacological treatment in elderly patients during pre- and post-graduate education of healthcare professionals.

\section{Use of non-steroidal anti-inflammatory drugs and risk of cardiovascular adverse effects in hospitalized patients}

The group of non-steroidal anti-inflammatory drugs (NSAIDs) is one of the most prescribed drug groups worldwide. Several NSAIDs are available over the counter; they are used by a large number of patients without prescription. The widespread use of non-steroidal antiinflammatory drugs is caused by the high prevalence of diseases causing acute or chronic pain in the population. Diseases accompanied by inflammation and fever also occur in a substantial number of patients. Adverse drug reactions of NSAIDs represent a serious medical problem because of the high number of exposed patients. Continuous analysis of analgesic usage is needed to improve the safety of analgesic therapy.

\section{Methods}

Retrospective data collection from documentation of patients hospitalized in the department of internal medicine of a district hospital; data were analyzed using methods of descriptive statistics.

Results

In our recent pilot study, data obtained from medical records of 112 patients receiving NSAIDs during hospitalization in the department of internal medicine were evaluated with focus on analgesic prescription and risk of cardiovascular adverse effects (Varga et al., 2010). The mean age was 63.7 years (SD, 15.0), 67\% of the patients in the study group were women. The most commonly used non-steroidal anti-inflammatory drug was metamizol (76 patients; $67.9 \%$ of the study group). Diclofenac (20; $17.9 \%)$, indomethacin $(16 ; 14.3 \%)$ and ketoprofen (14; $12.5 \%)$ were also used by a high number of patients.

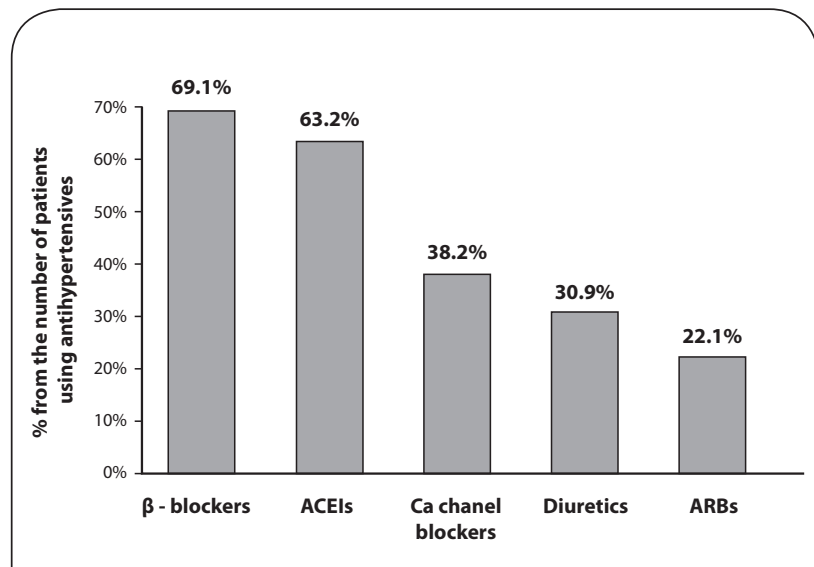

Figure 5. Drugs used in antihypertensive treatment in study group.

Preferential inhibitors of COX-2 were administered to 17 patients (nimesulide - 10; 8.9\%; meloxicam - 7; 6.3\%). Arterial hypertension, chronic heart failure and ischemic heart disease were the most frequent diagnoses indicating increased risk for development of cardiovascular adverse effects of NSAIDs (Table 3).

Administration of NSAIDs can lead to elevation of arterial blood pressure (Chan et al., 2009; White, 2007), the greatest risk is present in patients with controlled arterial hypertension using ACE inhibitors, angiotensin receptor blockers and beta-blockers (White, 2007). In our study group, the most frequently used antihypertensive drugs were beta-blockers and ACE inhibitors (Figure 5).

Results of the discussed pilot study need to be confirmed in a study with a large number of enrolled patients. The possible pathophysiological mechanisms leading to cardiovascular toxicity of NSAIDs will be studied in animal experiments.

\section{Ackowledgements}

This work was supported by grants VEGA 1/0135/09 and 1/0501/11, Ministry of Education, Slovak Republic.

\section{REFERENCES}

Babál P, Kristová V, Černá A, Janega P, Pecháňová O, Danihel L’, Andriantsitohaina R. (2006). Red wine polyphenols prevent endothelial damage induced by CCl 4 administration. Physiol Res 55: 245-251.

Babál P, Kristová V, Kriška M. (1996). Decreased endothelial loss after sulodexide administration assessed by in vitro vessel perfusion. Res Comm Pharmacol Toxicol 1: 119-126.

Babál P, Kriška M, Kristová V, Caňová R. (1992). Evaluation of endothelium loss by in vitro vessel perfusion using Millipore filters. Physiol Res 41: 359-362.

Babál P, Kriška M, Kristová V, Jakubovský J, Caňová R. (1987). Morphological changes of the arterial duct endothelium in conditions of the perfusion method. Čs fysio/ 36: 320-322 [in Slovak]. 
Cassin S, Kristová V, Davis T, Kadowitz P, Gause G. (1991). Tone-dependent responses to endothelin in the isolated perfused fetal sheep pulmonary circulation in situ. J Appl Physiol 70: 1228-1234.

Chan CC, Reid CM, Aw TJ, Liew D, Haas SJ, Krum H. (2009). Do COX-2 inhibitors raise blood pressure more than nonselective NSAIDs and placebo? An updated meta-analysis. J Hypertens 27: 2332-2341.

Dedík L, Ďurišová M, Svrček V, Vojtko R, Kristová V, Kriška M. (2003). Computer-based methods for measurement, recording and vessel responses in vitro. Meth Find Exp Clin Pharmacol 25: 441-445.

Fick DM, Cooper JW, Wade WE et al. (2003). Updating the Beers criteria for potentially inappropriate medication use in older adults. Arch Intern Med 163: $2716-2724$.

Gaddi A, Galetti C, Illuminati B, Nascetti S. (1996). Meta-analysis of some results of clinical trials on sulodexide therapy in peripheral occlusive arterial disease. J Int Med Res 24: 389-406.

Kovalčík V. (1963). The response of the isolated ductus arteriosus to oxygen and anoxia. J Physiol 165:185-197.

Kristová V, Babál P, Jablonická K, Kriška M. (1995). Study of endothelium-protective effects of sulodexide. Pharmacol Res 31: 248

Kristová V, Djibril MN, Fačkovcová D, Kriška M, Kurtanský A. (2002). Comparison of vasoconstrictor responses to selected NSAIDs in rabbit renal and femoral arteries. Bratisl Lek Listy 103: 50-53.

Kristová V, Kiss A, Pirnik Z, Kriška M, Ježová D. (2006). Effect of pentoxifylline on endothelaemia and hypothalamic-pituitary-adrenocortical axis activation in female rats under stress exposure. Gen Physiol Biophys 25: 81-89.

Kristová V, Kriška M, Babál P, Djibril MN, Slámová J, Kurtanský A. (2000). Evaluation of endothelium-protective effects of drugs in experimental models of endothelial damage. Physiol Res 49: 123-128.

Kristová V, Kriška M, Caňová R, Hejdová E, Kobzová D, Dobrocký P. (1993). Endothelial changes following repeated effects of vasoconstrictive substances in vitro. Acta Physiol Hung 81: 363-370.

Kristová V, Kriška M, Caňová R. (1986). Reactivity of the fetal and neonatal pulmonary artery in vitro. Bratisl lek Listy 86: 287-294 [in Slovak].

Kristová V, Kriška M, Vojtko R, Kurtanský A. (2000). Effect of indomethacin and deendothelisation on vascular responses in the renal artery. Physiol Res 49: 129-133.

Kristová V, Líšková S, Sotníková R, Vojtko R, Kurtanský A. (2008). Sulodexide improves endothelial dysfunction in streptozotocin-induced diabetes in rats. Physiol Res 57: 491-494.

Kriška M, Babál P, Kristová V. (1989). The assessment the reactivity of perfused vessels in relation to the endothelium. Čs fysio/ 38: 153 [in Slovak].

Kriška M, Kovalčík V. (1973). Concerning the mechanism of constriction of the arterial duct in response to oxygen. Folia Fac Med Univ Comenianae Bratisl XI: 145-195 [in Slovak].
Kriška M, Štvrtinová V, Kristová V, Ambrózy E. (2002). Possibilities of pharmacological intervention in derangements of peripheral circulation. Slovakofarma Rev 12: 10-14 [in Slovak].

Lagaud GJ, Masih-Khan E, Kai S, van Breemen C, Dubé GP. (2001). Influence of type II diabetes on arterial tone and endothelial function in murine mesenteric resistance arteries. J Vasc Res 38: 578-589.

Líšková S, Kuneš J, Zicha J (2007). Nifedipine-sensitive vascular reactivity of femoral arteries in WKY: The effects of pertussis toxin pretreatment and endothelium removal. Physiol Res 56: 663-666.

McLeod PJ, Huang AR, Tamblyn RM et al. (1997). Defining inappropriate practices in prescribing for elderly people: a national consensus panel. CMAJ 156: 385-391.

Onder G, Landi F, Liperoti R et al. (2005). Impact of inappropriate drug use among hospitalized older adults. Eur J Clin Pharmacol 61: 453-459.

Rajec J, Tisoňová J, Kriška M, Kristová V, Vojtko R, Dukát A, Ambrózy E, Slyško R, Varga I. (2007). Endothelaemia- a marker of vascular damage. Bratisl Lek Listy 108: 403-405.

Sivitz WI, Wayson SM, Bayless ML, Sinkey CA, Haynes WG. (2007). Obesity impairs vascular relaxation in human subjects: hyperglycemia exaggerates adrenergic vasoconstriction arterial dysfunction in obesity and diabetes. $J$ Diabetes Complications 21: 149-157.

Smieško V, Kriška M, Kovalčík V. (1978). Bayliss myogenic response in the isolated ductus arteriosus of guinea-pig and rabbit fetuses. Experientia 34 745-746.

Turnheim K. (2003). When drug therapy gets old: pharmacokinetics and pharmacodynamics in the elderly. Exp Gerontol 38: 843-853.

Varga Z, Kriška M, Kristová V, Hudec. (2010). Prescription of NSAIDs and risk of cardiovascular adverse effects in hospitalized patients. Rheumatologia 24: 87-90.

Vojtko R., Villaris R., Petrová M., Líšková S., Kristová V. (2010). Modulation of diabetic rat vessel reactivity induced by pycnogenol and sulodexide and its alternative evaluation. Acta Medica (Hradec Králové) 53: 200-201.

Wawruch M, Fialová D, Žikavská M, Kuželová M, Ježová D, Vinšová J, Kristová V, Topinková E. (2008). Use of potentially inappropriate drugs in elderly patients in the territory of former Czechoslovakia. Klin Farmakol Farm 22: 108-112 [in Slovak].

White WB. (2007). Cardiovascular effects of the cyclooxygenase inhibitors. Hypertension 49: 408-418.

Zúrová-Nedelčevová J, Navarová J, Drábiková K., Jančinová V, Petríková M, Bernátová I, Kristová V, Šnirc V, Nosálová V, Sotníková R. (2006). Participation of reactive oxygen species in diabetes - induced endothelial dysfunction. Neuro Endocrinology letters 27: 168-171. 